\section{PCR detection of the Pvull (Ea) RFLP at the human phenylalanine hydroxylase (PAH) locus}

\author{
B.Dworniczak, N.Wedemeyer, A.Eigel and J.Horst* \\ Institut für Humangenetik der Universität, Vesaliusweg \\ 12-14, D-4400 Münster, FRG
}

Source/Description: phPAH 247, a human phenylalanine hydroxylase cDNA clone 2448 bp in length, was previously reported to detect at least 10 polymorphic sites at the PAH locus (1). We have used this cDNA to identify a lambda clone which has inserted genomic DNA covering exon 2, intron 2 and exon 3 of the PAH gene. Subsequently we isolated the $4 \mathrm{~kb}$ BgllIfragment harbouring exon 2 and flanking intronic sequences. Using this plasmid clone we were able to map the precise location of the PvuII polymorphic site which resides within this fragment.

Polymorphism: PvuII (CAG/CTG) identifies a two allele polymorphism with fragments of either $19 \mathrm{~kb}(-)(\mathrm{E} 1)$ or $6 \mathrm{~kb}$ $(+)(E 2)$ in length.

Frequency: Studied in 202 unrelated Europeans:

$\begin{array}{llll}\text { Non-PKU: } & \text { E1 } 0.271 & \text { PKU: } & \text { E1 } 0.087 \\ & \text { E2 } 0.729 & & \text { E2 } 0.913(2)\end{array}$

Chromosomal Location: The human PAH gene has been localised to 12q22-q24 (3).

Mendelian Inheritance: Mendelian inheritance was demonstrated in all two-generation families tested.

Other Comments: Oligonucleotides used for amplification are 5'-GGCATGACTGGATACGATTAG-3' and 5'-CTAGACTCAGAATGCCTGGG-3'. PCR was performed using $200 \mathrm{ng}$ genomic DNA and 50 pmoles of each primer. Initial denaturation for $240 \mathrm{sec}$ was followed by 30 cycles of $40 \mathrm{sec}$ at $93^{\circ} \mathrm{C}, 40$ sec at $72^{\circ} \mathrm{C}$ and $70 \mathrm{sec}$ at $50^{\circ} \mathrm{C}$. The final extension was at $72^{\circ} \mathrm{C}$ for $300 \mathrm{sec}$. PCR amplification yields a $374 \mathrm{bp}$ fragment. If the polymorphic site is present this amplification product can be cleaved by PvuII into a 225 bp and a 149 bp long fragment (fig). Our analyses revealed that this polymorphic site is located in the second intron of the PAH gene $1.4 \mathrm{~kb}^{\prime}$ to exon 2 .

Acknowledgement: This work is supported by the Deutsche Forschungsgemeinschaft and the Bundesminister für Forschung und Technologie.

References: 1)Lidsky et al. (1985) Am. J. Hum. Gen. 37, 619-634. 2)Daiger et al. (1989) Am. J. Hum. Gen. 45, 310-318. 3)Lidsky et al. (1985) Proc. Natl. Acad. Sci. USA 82, 6221-6225.

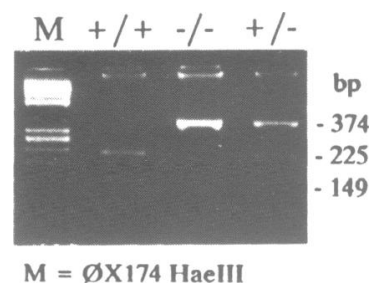

* To whom correspondence should be addressed

\section{PCR detection of the Bglll RFLP at the human phenylalanine hydroxylase (PAH) locus}

B.Dworniczak, N.Wedemeyer and J.Horst*

Institut für Humangenetik der Universität, Vesaliusweg 12-14, D-4400 Münster, FRG

Source/Description: phPAH 247, a human phenylalanine hydroxylase cDNA clone 2448 bp in length, was previously reported to detect at least 10 polymorphic sites at the PAH locus (1). We have used this cDNA to identify lambda clones covering the genomic $5^{\prime}$ region of the gene and subsequently to isolate a $3.6 \mathrm{~kb}$ BglII-fragment harbouring exon 1 and flanking intronic sequences. Using this fragment which represents the larger band of the BglII polymorphism (1) we were able to map the precise location of the polymorphic site.

Polymorphism: BglII (A/GATCT) identifies a two allele polymorphism with fragments of either $3.6 \mathrm{~kb}(-)$ (D1) or 1.7 $\mathrm{kb}(+)(\mathrm{D} 2)$ in length.

Frequency: Studied in 202 unrelated Europeans:

Non-PKU: D1 0.729 D2 0.271 PKU: D1 0.891 D2 0.109 (2)

Chromosomal Location: The human PAH gene has been localised to $12 \mathrm{q} 22-\mathrm{q} 24.2$ (3).

Mendelian Inheritance: Mendelian inheritance was demonstrated in all two-generation families tested.

Other Comments: Oligonucleotides used for amplification are 5'-GCAGGAAACTCTCTGACTTTGG-3' and 5'-TGGCAGTTCTGGAGGCCAGA-3'. PCR was performed using $200 \mathrm{ng}$ genomic DNA and 50 pmoles of each primer. Initial denaturation for $240 \mathrm{sec}$ followed by 30 cycles of $40 \mathrm{sec}$ at $93^{\circ} \mathrm{C}, 40 \mathrm{sec}$ at $72^{\circ} \mathrm{C}$ and $70 \mathrm{sec}$ at $50^{\circ} \mathrm{C}$. The final extension was at $72^{\circ} \mathrm{C}$ for $300 \mathrm{sec}$. PCR amplification yields a $290 \mathrm{bp}$ fragment. If the polymorphic site is present this amplification product can be cleaved by BglII into a 209 bp and a 81 bp long fragment (fig). Sequence analyses revealed that the polymorphic site is located 55 bp $3^{\prime}$ to exon 1 .

Acknowledgement: This work is supported by the Deutsche Forschungsgemeinschaft and the Bundesminister für Forschung und Technologie.

References: 1)Lidsky et al. (1985) Am. J. Hum. Gen. 37, 619-634. 2)Daiger et al. (1989) Am. J. Hum. Gen. 45, 310-318. 3)Lidsky et al. (1985) Proc. Natl. Acad. Sci. USA $82,6221-6225$.

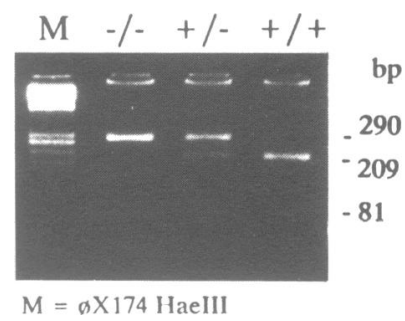

\footnotetext{
* To whom correspondence should be addressed
} 